\title{
EXTIRPATION AND TRANSPLANTATION OF THE THYMI IN LARVAE OF RANA SYLVATICA
}

\author{
(With flve plates-39 figures) \\ MARGARET MORRIS HOSKINS, \\ Medical College of Virginia, \\ RICHMOND
}

INTRODUCTION

The following study has been prepared from notes and preserved material left by the late E. R. Hoskins. The experiments were made by him in the spring of 1919 at the University of Pittsburgh. They consisted of extirpations and transplantations of the thymi of larvae of Rana sylvatica, planned with particular idea of determining the relation of these glands to the lymphoid organs which they so closely resemble. In a previous paper, this investigator (Hoskins, '18) expressed the belief that the thymus is a lymphoid organ, producing no internal secre-. tion. The suggestion was made that "in the lower animals there is relatively little lymphoid tissue other than the spleen and thymus, and experiments with the thymus in these forms should, therefore, be very instructive on account of the relative simplicity of the problem.".

The experiments herein reported were of three sorts: complete extirpation, unilateral extirpation, and transplantation of thymic tissue. By making such a series of operations it was possible to study and compare normal animals, individuals with an excess of thymic tissue, those that had half the normal amount, and those that were entirely without any. In the following pages we shall consider the effect of the operations on the growth of the animals, on the normal thymi in cases where they were left intact, on the spleen, and on the endocrine organs.

\section{MATERIAL AND METHODS}

The tadpoles chosen for the experiments were from 11 to $16 \mathrm{~mm}$. in length, and the operations were performed with fine knives and iridectomy scissors, the animals being anesthetized 
with chlorotone $(0.02 \%$ in $0.3 \%$ sodium chloride). When extirpation was to be performed, an incision was made at the side of the animal's head, and the thymus anlage was cut out. In making a graft, a flap of ectoderm was turned back on the lower jaw, and the thymic tissue which had been taken from another animal was implanted between the ectoderm and the muscles. The normal thymi of the hosts were not disturbed in the transplantation experiments.

The material chosen for histological study is largely from animals which had just completed metamorphosis, but some were also studied that were killed when at their maximum size, before the beginning of metamorphosis. The selection of a single, easily recognized stage eliminates the possibility of error arising from -comparing tadpoles of the same size but of different stages of development.

Two methods were used in the study of the preserved material. Several animals from each set of experiments were studied from paraffin sections, and a large number of specimens were autopsied under the binocular microscope. The organs to be studied were dissected out from the surrounding tissues, and their outlines traced with the assistance of a camera lucida. The method is rather a crude one, but gives a general idea of the comparative sizes of the organs. It was expected that if significant variations of size were found, more exact measurements would be made from reconstructions, but the negative results obtained with the quicker method did not warrant the use of the more tedious process.

\section{LITERATURE}

Thymectomy has been performed by a number of investigators, on various animals. The results of all the experiments are critically summarized in a recent paper by Park and McClure ('19) and need not be reviewed in detail here. When the evidence is sifted, we find that thymectomy has not been satisfactorily shown to have a perceptible effect on the growth and development of any animals nor on any of their organs. In all cases in which experiments have been properly performed and controlled, they have yielded only negative results. Most of the work has been done an mammals, but some experiments with amphibia give similar results. It is certain that the high mor- 
tality among the tadpoles operated on by Abelous and Billard ('96) was the result of an infection rather than of the operations. The experiments of Hammar ('05) showed that the thymus is not essential to the life of the tadpole. Adler ('14) reached the same conclusion, but claimed to have observed changes in the thyroids of thymectomized larvae, and hypertrophy of the gonads. He draws his conclusions from but three specimens, hence they amount to little more than guesses. Allen ('20) has extirpated the thymus from tadpoles, and studied a much larger number of specimens without finding any effect on their gonads or thyroids.

Thymus transplantation has not been performed by so large a number of investigators, and those who have done this operation have usually found that the graft was resorbed. Gebele has reported that the operation prevents the tetany which follows the extirpation of the thyroid and parathyroid, but others have been unable to confirm this statement. Dustin, who has worked on thymic grafts in amphibians and reptiles, has studied the different cellular elements in the grafts themselves, but not their effect on the rest of the body.

Other work on the thymus which is of particular interest in connection with the present study is that of Uhlenhuth. His views are not based on operative work, but on feeding experiments, and his general conclusion is that the thymus and the parathyroids act antagonistically in the body, the thymus producing a toxic substance which is neutralized by the parathyroids. Any disturbance of the balance existing between these organs, such as is caused by feeding thymus substance, results in a tetany which is similar to tetania parathyreopriva. The results obtained by Gebele are in opposition to this theory, since Gebele found that excess of thymic tissue prevented tetania parathyreopriva, instead of causing it.

Recently Dustin ('20) has proposed a different theory of the function of the thymus. He has made a very extensive study of the histology of the thymi in frog larvae, using both normal and thyroid fed animals at various stages of development. According to his observations, the small cells of the thymus are derived from the larger elements, and represent a stage in the loss of nuclein which the gland undergoes. The function of the organ is the elaboration of nuclein and giving it to the body. 
Under conditions resulting from thyroid feeding the process goes on much more slowly. Nuclein is supplied to the body by the ingested thyroid substance and is not removed from the thymus, which shows a greater number of large cells than the thymus of a normal tadpole.

\section{RESULTS}

1. Growth and development: None of the operations performed seems to have affected the growth and development of the animals. Some measurements were taken during the growth period from the time of the operation until the animals attained their maximum size, and no significant difference between operated and normal animals was observed. As the tadpoles approached the period of metamorphosis each one was isolated, and

\begin{tabular}{|c|c|c|c|c|c|}
\hline & \multicolumn{3}{|c|}{ TADPOLE } & \multicolumn{2}{|c|}{ FROG } \\
\hline & Max. I & Length & Max. Volume & Length & Volume \\
\hline $\begin{array}{r}\text { Control } \\
4 / 3 \ldots \ldots \ldots \ldots \ldots \ldots \\
3 / 29 \ldots \ldots \ldots \ldots \ldots \\
4 / 21 \ldots \ldots \ldots \ldots \ldots \\
4 / 24 \ldots \ldots \ldots \ldots \ldots\end{array}$ & $\begin{array}{r}39.0 \\
38.5 \\
43.5 \\
\cdots\end{array}$ & $\begin{array}{l}16.1 \\
16.9 \\
17.4 \\
\ldots\end{array}$ & 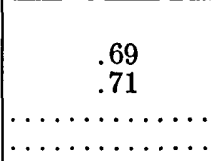 & $\begin{array}{l}13.0 \\
13.8 \\
14.3 \\
11.6\end{array}$ & $\begin{array}{l}.28 \\
.34 \\
.35 \\
.22\end{array}$ \\
\hline $\begin{array}{r}\text { Complete Extirpation } \\
4 / 10 \ldots \ldots \ldots \ldots \ldots \\
4 / 11 \ldots \ldots \ldots \ldots \\
4 / 21 \ldots \ldots \ldots \ldots\end{array}$ & $\begin{array}{l}38.6 \\
39.3 \\
39.8\end{array}$ & $\begin{array}{l}16.2 \\
16.2 \\
17.1\end{array}$ & & $\begin{array}{l}13.2 \\
12.6 \\
13.8\end{array}$ & $\begin{array}{l}.25 \\
.27 \\
.33\end{array}$ \\
\hline $\begin{array}{l}\text { Partial Extirpation } \\
4 / 24 \ldots \ldots \ldots \ldots \ldots \\
4 / 25 \ldots \ldots \ldots \ldots \ldots\end{array}$ & $\begin{array}{l}39.3 \\
42.7\end{array}$ & $\begin{array}{l}17.1 \\
15.5\end{array}$ & $\begin{array}{l}.64 \\
\ldots .\end{array}$ & $\begin{array}{l}11.5 \\
13.5\end{array}$ & $\begin{array}{l}.17 \\
.29\end{array}$ \\
\hline $\begin{array}{r}\text { Implantation } \\
4 / 11 \ldots \ldots \ldots \ldots \\
4 / 21 \ldots \ldots \ldots \ldots\end{array}$ & $\begin{array}{l}40.0 \\
37.4\end{array}$ & $\begin{array}{l}\ldots \\
\ldots\end{array}$ & & $\begin{array}{l}12.9 \\
11.8\end{array}$ & $\begin{array}{l}.27 \\
.19\end{array}$ \\
\hline
\end{tabular}

was measured daily, so that we might be sure to have a record of its maximum size. Both body-length and total length were recorded, and the volume was measured by displacements. Table I shows a summary of these measurements, and of the measurements of the frogs developing from the experimental and the control subjects. Neither extirpation nor transplantation has any effect on the size of the animals. The only case in which a noticeable difference is present is in the three groups for $4 / 21$. Here both the hosts in the transplantation experiments and the 
completely thymectomized animals were smaller than the controls. This is doubtless an accidental variation; certainly it cannot be directly traced to the amount of thymic tissue present.

None of the experimental animals showed any loss of vigor, or any signs of tetany.

2. Grafts and Normal Thymi: Autopsies and sections showed that the operations were generally successful. Regenerated thymi were rare, while the grafts grew well in every case. Figures 1, 2 and 3 show sections through a graft and a normal thymus. They illustrate the position of the graft and the size relation between it and the normal thymus. The more ventral portion of the graft (A. Figs. 1 and 2) is undoubtedly the original tissue, while the smaller part (B. Fig. 2) is an off-shoot from it which has grown in behind the cartilage of the jaw. Figures 14 and 18 represent the outlines of the grafts obtained from autopsies. The thymi from the same frogs are shown in Figures 13 and 17, and it is evident that the grafts have more than doubled the amount of thymic tissue in the body.

Histologically, the grafts resemble the normal thymus of a tadpole. During metamorphosis the normal thymus undergoes a change which is represented in figures 6 and 9 . The first of these shows the gland before metamorphosis. There are present in it a number of very large vesicular nuclei, which disappear during metamorphosis. According to Dustin ('20) they undergo "diminishing" divisions. Their place is taken in the thymus of the young frog by smaller vesicular nuclei. Connective tissue elements, also, which are prominent in the thymus of the tadpole, are less noticeable after metamorphosis, and the proportion of small dark nuclei is increased. The figures are taken from the central part of the thymus in both cases. The thymus of the tadpole has a cortex in which there are more dark nuclei than at the center, and this cortex increases in relative amount during metamorphosis.

A graft from a tadpole is shown in figure 4, and its close resemblance to the normal larval thymus (Fig. 6) is noticeable. This figure, also, is taken from the center of the graft which had about as much cortex as a larval thymus. The grafts do not undergo the same changes as the normal thymi at the time of metamorphosis. Figure 5 shows a portion of a graft from a frog, 
illustrating its similarity to the normal larval thymus and the larval graft.

The normal thymi were studied, both from autopsies and from sections, to see if any regulation of the amount of thymic tissue takes place. Figures 12-19, which are representative of the entire series of autopsies, show that there is no regulation. Figures 12, 13, 14 and 15 show the different amounts of thymic tissue in three individuals with the length of $121 / 2 \mathrm{~mm}$. each. Figure 12 represents the two thymi of a normal frog, figures 13 and 14 the two thymi and the graft of a host in a transplantation experiment, and figure 15 the single thymus of a frog which had undergone unilateral extirpation. Figures 16, 17, 18 and 19 give a similar series for $12 \mathrm{~mm}$. frogs. It might appear from the upper row of figures that the graft had exerted a retarding influence on the thymi shown in figure 13, since they are smaller than those of the control, but the condition is not repeated in the second series, in which the thymi of the host are larger than those of the normal animal. No proof of regulation is seen in the single thymus remaining after unilateral extirpation. In the smaller animals (Figs. 16-19) it is larger than either of the glands from the normal animal, but in the other series (Figs. 12-15) it is about the same size. The method of measurement, which is simply a comparison of outlines of the organs, is not very accurate, but as far as it goes it shows no indication that there is regulatory hypertrophy or atrophy of thymic tissue in these experiments.

The only detected effect of these operations on the thymus was a slight change in the histological appearance of the single thymus after unilateral extirpation. This is illustrated in figures 10 and 11, which represent the remaining gland in a tadpole and a frog respectively. In the tadpole the large cells have already become considerably smaller than those of the thymus of a normal larva (Fig. 6). The picture presented is scarcely distinguishable from that of the normal thymus of a frog. Also, in the single thymus after metamorphosis, a condition is found which may be supposed to be a later stage in the development of the gland. Pycnotic cells are not infrequent (p Fig. 11) although they are not to be seen in the normal thymus immediately after metamorphosis. Dustin has stated ('20) that the only activity of the organ which is morphologically demonstrable is the multi- 
plication of cells, with increase of basichromatin and final pycnosis. It appears that though there is no compensatory hypertrophy of the gland, the rate of this activity is more rapid in the thymus left after a unilateral extirpation than in the glands of a normal animal.

Spleen: If the thymus is to be classed as a lymphoid organ, it is possible that its extirpation would affect the spleen, which is the only other large mass of lymphoid tissue in the body of the frog. Such does not, however, seem to be the case. Figures 20, 21,22 and 23 show the spleens from a series of frogs with varying amounts of thymic tissue, and no significant size-differences are to be seen. Neither does a microscopic examination of the tissues show any effect of the operations.

Thyroids and Parathyroids: The thyroids have been studied from paraffin sections, as it is difficult to dissect out the whole gland on account of its irregular shape. I have not observed any significant changes in the form, size, or histological appearance of the thyroids of operated animals. My results on this point agree with those of Allen ('20) and differ from Adler's ('14). The thyroids of normal animals vary so much in size that a large amount of material must be studied in order to reach a definite conclusion with regard to the effect of the experiments on this gland. Within the limits of the material I have examined, no effect of thymectomy or grafting was to be seen in the thyroids.

The same condition is found in the parathyroids. Particular interest attaches to the condition of these glands in the frogs in which large amounts of thymic tissue have been implanted, owing to the theory of Uhlenhuth regarding the interrelation of the thymi and parathyroids. Nothing has been brought to light by this study which points to any special relation between these organs. The parathyroids of the thymectomized and normal frogs and tadpoles appear like those of the hosts for large grafts. They were studied from sections on account of their small size.

Hypophysis: Hypophyses were dissected out from a number of normal and completely thymectomized animals. From the first few autopsies and from sectioned material it appeared that the hypophysis had hypertrophied in the thymectomized specimens. Further investigations, however, made it seem doubtful whether this was anything but an accidental variation. 
Figure 24 shows a median longitudinal section from a thymectomized frog, and figure 1 from a control. There is a striking difference in the size of the inferior lobe, particularly. Figures 26 and 27, however, show a pair which are practically equal in size. They were taken from a thymectomized and normal frog, respectively, the two being the same length $(12 \mathrm{~mm}$.) and nearly the same volume. Figure 28 shows the outline of the largest hypophysis found. It is from a thymectomized frog $13 \mathrm{~mm}$. in length. The figure beside it (29) is from a normal animal of the same size. Figures 30 and 31 show a similar relation in hypophysis from thymectomized and normal frogs of $131 / 2 \mathrm{~mm}$. There seems to be a tendency for the hypophyses of thymectomized frogs to be abnormally large, especially in the larger animals. I have not found any of these glands in the normal specimens, which are as large as those shown in figures 28 and 30 . I should hesitate, however, to say that the hypophysis had undergone a compensatory hypertrophy without examining a much larger amount of material than I have on hand. A histologieal study shows no change in the appearance of the gland as a result of the operations. The hypophysis of frogs with one thymus and those which had thymic tissue implanted in them are also normal as far as I have observed, and these show no variation in size.

Gonads: The gonads of all four groups of animals were studied from autopsies and representative specimens of testes are shown in figures 32 to 39 . It has been found that castration delays the involution of the thymus in some animals, and we might expect this interrelation to be expressed by hypertrophy of the gonads after thymectomy. This does not occur, however. The two series, figures 32 to 35 and figures 36 to 39 , are arranged in order according to the amount of thymic tissue present in the animal. They show no consistent differences in size which can be thought to indicate an influence of the thymus. The size relations seen in the ovaries are the same as these figures, and neither gonad shows any change upon histological examination. Here, also, our results agree with Allen's, and disagree with Adler's.

\section{DISCUSSION}

It is impossible to draw any definite conclusion as to the function of the thymus from the foregoing study. Owing to the great variation in the size of the organs of the normal frogs one 
cannot obtain satisfactory results without a very large amount of material. Moreover, the smallness of the individual organs makes direct weight or volume determinations impossible, and methods of measurement must be either crude or excessively time consuming. The plan of the study was to look for any striking changes in the sizes of organs; and in case these presented themselves, to carry the work further by means of reconstruction. There is no indication, however, that such an undertaking with this material would be worth while.

A few negative results of the study may be pointed out. We agree with Allen that the thymus is not at all necessary for the life and development of the frog larvae, and that its loss does not affect the gonads or thyroids. We have also shown that excess of thymic tissue does not affect the tadpole in any perceptible way. The only endocrine gland which seems to be affected by any of the operations is the hypophysis, which is abnormally large in some cases after complete thymectomy. Since this gland does not always show evidence of hypertrophy, it is hardly likely that the overgrowth, when present, is of a compensatory nature.

Another point which is of some interest is the complete absence of regulation of the amount of thymic tissue. The larva seems to thrive as well with half as much or twice as much as the normal amount, and no attempt is made to restore the usual condition. This should be considered in judging the lack of effect produced by the operations on the spleen. If the thymus remaining after unilateral extirpation undergoes no hypertrophy, it is hardly to be expected that the spleen would show any overgrowth, even though it were of the same nature as the thymus.

On the ground of this lack of regulation, also, it would seem more reasonable to class the thymus among the lymphoid organs than to place it with the glands of internal secretion. It is known that the amount of lymphoid tissue in the body may vary greatly without producing any noticeable effects, while increase or loss of a hormone-producing gland is followed by some disturbances of metabolism and by easily recognized changes, especially in other glands of the endocrine series.

SUMMARY

1. Complete thymectomy does not affect the spleen of the larva or frog, nor any of the other organs with the possible excep- 
tion of the hypophysis. The hypophysis appeared abnormally large in some of the thymectomized specimens, but the difference in size is probably not a true compensatory hypertrophy.

2. After partial (unilateral) thymectomy there is no attempt at compensatory hypertrophy on the part of the remaining thymus. Certain cellular changes go on more rapidly in the remaining thymus than they do in the glands of normal animals. No other organs are affected by unilateral thymectomy.

3. Grafting thymic tissue into a tadpole does not affect the size or structure of the normal thymi, the spleen, or any other organs.

4. Neither grafting nor extirpating the thymus affects the growth and development of the larvae.

\section{BIBLIOGRAPHY}

Abelous, J. E., and Blllard: Recherches sur les fonctions du thymus chez la Grenouille. Arch. de physiol, norm. et path. (Paris), 1896, 47, 898-907.

Adler, Leo: Metamorphosenstudien an Batrachierlarven. Arch. $t$. Entwcklngsmchn. (Leipz.), 1914, 40, 1-17.

Allen, B. M.: The results of earliest removal of the thymus gland in Rana piplens tadpoles. J. Exper. Zool. (Phila.), 1920, 30, 189-200.

Dustin, A. P.: La potentialité des eléments thymiques etudiés par la methode des greffes. Bull. soc. f. sc. med. et nat. de Bruxelles, 1911. 69, 76-82.

- Recherches d'histologie normale et experimentale sur le thymus de Rana fusca. Arch. de biol. (Llege), 1913, 28, 1-10.

- Recherches d'histologie normale et experimentale sur le thymus des amphibiens anoures. Ibid., 1920, 30, 601-693.

Gebele: Ueber experimentelle Versuche mit Basedowthymus. I. Vers. bayerisch. Chirurg. zu Munchen, Beitr. z. klin. Chir. (Tübingen), 1911, 76, 823-828.

Hammạ, J. E.: Ist die Thymusdruse beim Frosch ein lebenswichtiges Organ? Arch. f. d. ges. Physiol. (Bonn), 1905, 110, 337-350.

Hoskins, E. R.: Is there a thymic hormone? Endocrinol. (Los Angeles), 1918, 2, 241-257.

Park, E. A. and McClure, R. D.: The results of thymus extirpation in the dog. Am. J. Dis. of Child. (Chicago), 1919, 18, 317-524.

Uhlenhuth, E.: The antagonism between thymus and parathyroid glands. J. Gen. Physiol. (Balt.), 1918, 1, 23-32.

- Further proof of the antagonism existing between the thymus and the parathyroid. Proc. Soc. Exper. Biol. \& Med. (N. Y.), 1918, 16, 70-72. 


\section{PLATES}

Downloaded from https://academic.oup.com/endo/article-abstract/5/6/763/2771563 by East Carolina University user on 04 April 2018 


\section{PLATE I.}

Fig. 1. Sagittal section, showing largest section of graft (A).

Fig. 2. Sagittal section, showing two parts of graft (A and B). graft.

Fig. 3. Sagittal section through thymus (T) with small part of 


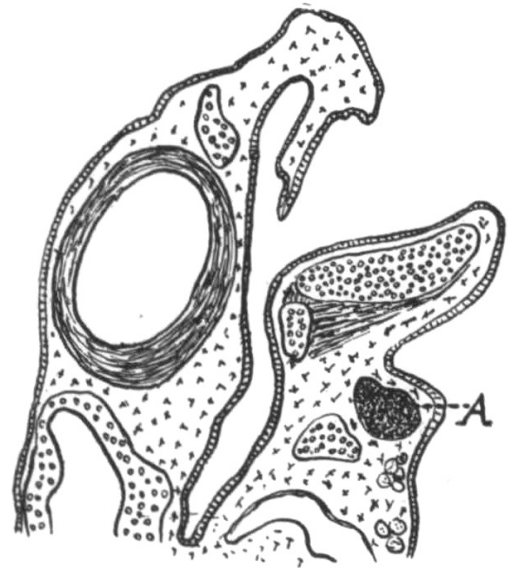

1.

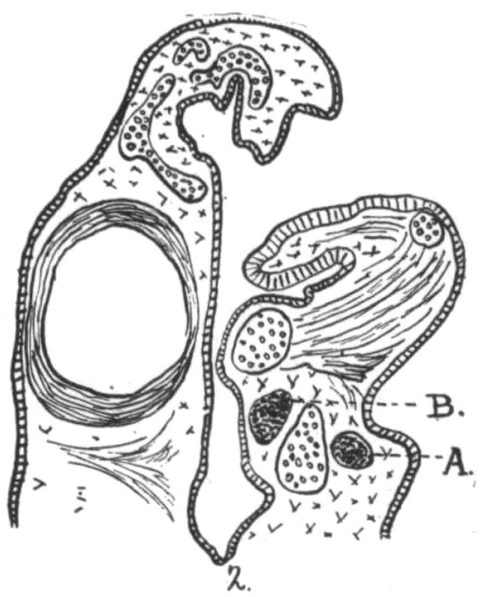

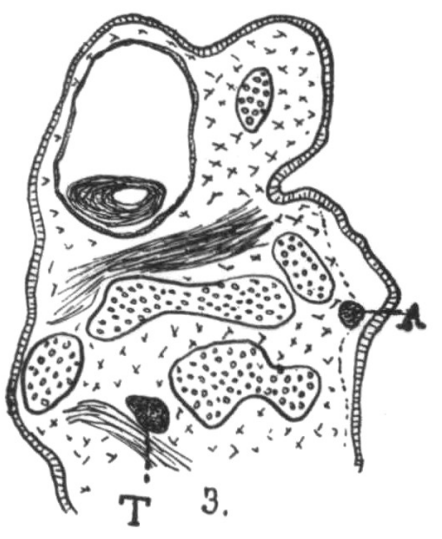




\section{PLATE II.}

Fig. 4. Graft from tadpole.

Fig. 5. Graft from frog.

Fig. 6. Thymus from normal tadpole.

Fig. 7. Thymus from tadpole with graft.

Fig. 8. Thymus from frog with graft.

Fig. 9. Thymus from normal frog.

Fig. 10. Thymus from tadpole after unilateral thymectomy.

Fig. 11. Thymus from frog after unilateral thymectomy.

(Note pycnotic nuclei, at $\mathrm{p}-$ ) 

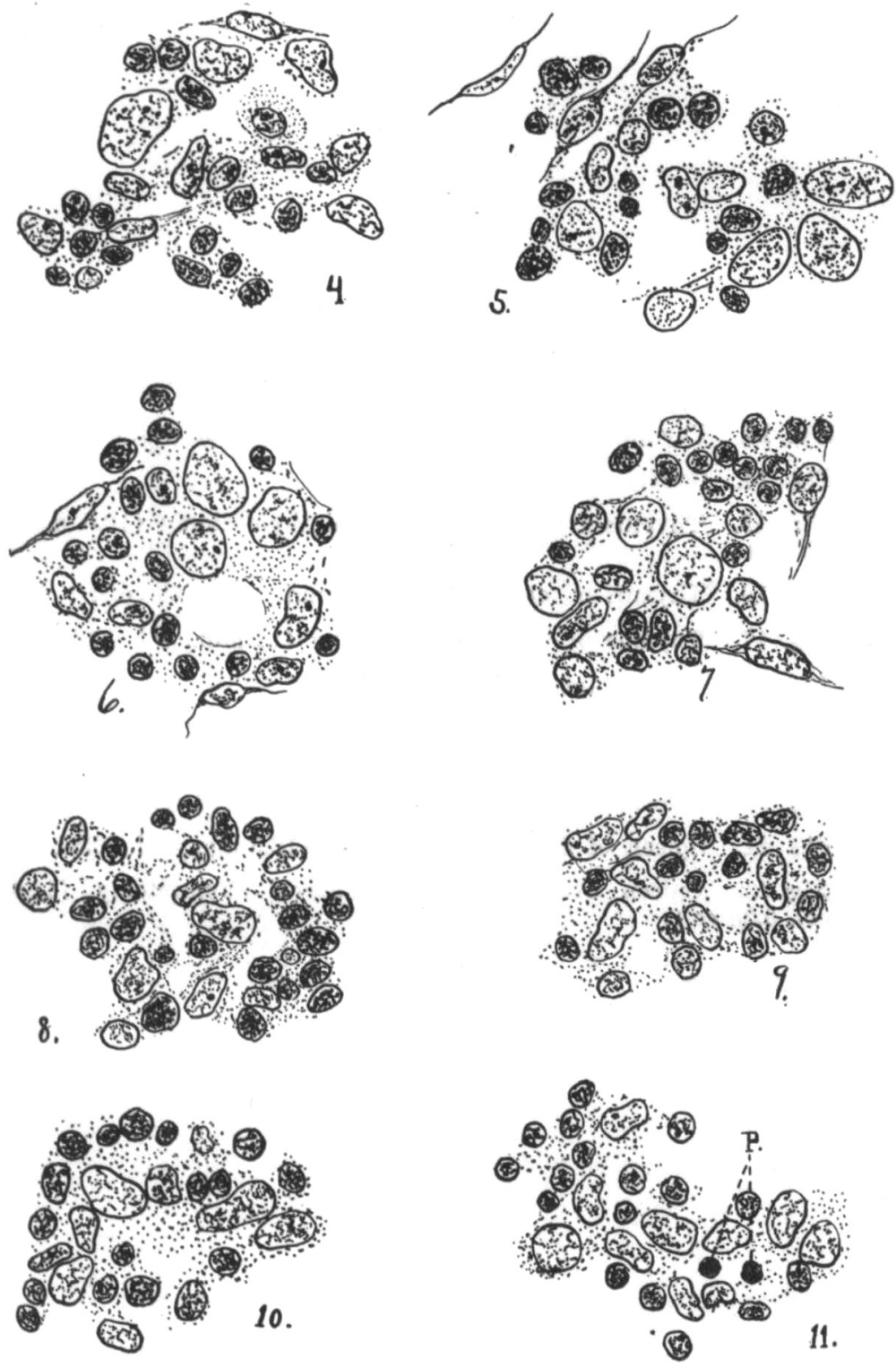


\section{PLATE III.}

Fig. 12. Thymus normal frog ( $12.5 \mathrm{~mm}$., vol. $0.22 \mathrm{cc}$.).

Fig. 13. Thymus of frog after grafting (12.5 mm., vol. $0.28 \mathrm{cc}$.).

Fig. 14. Graft, same frog as fig. 13.

Fig. 15. Thymus frog after unilateral thymectomy $(12.5 \mathrm{~mm}$., vol. $0.25 \mathrm{cc}$.).

Fig. 16. Thymus of normal frog (12 mm., vol. $0.20 \mathrm{cc}$.).

Fig. 17. Thymus of frog after grafting ( $12 \mathrm{~mm}$., vol. $0.18 \mathrm{cc}$.).

Fig. 18. Graft, same frog as fig. 17.

Fig. 19. Thymus of frog after unilateral thymectomy $(12 \mathrm{~mm}$., vol. $0.18 \mathrm{cc}$.).

Fig. 20. Spleen, normal frog (12.5 mm., vol. 0.22 cc.).

Fig. 21. Spleen of frog after grafting $(12.5 \mathrm{~mm}$., vol. $0.28 \mathrm{cc}$.).

Fig. 22. Spleen of frog after unilateral thymectomy (12.5 mm., vol. $0.25 \mathrm{cc}$.).

Fig. 23. Spleen of frog after complete thymectomy $(13 \mathrm{~mm}$., vol. $0.3 \mathrm{cc}$.). 

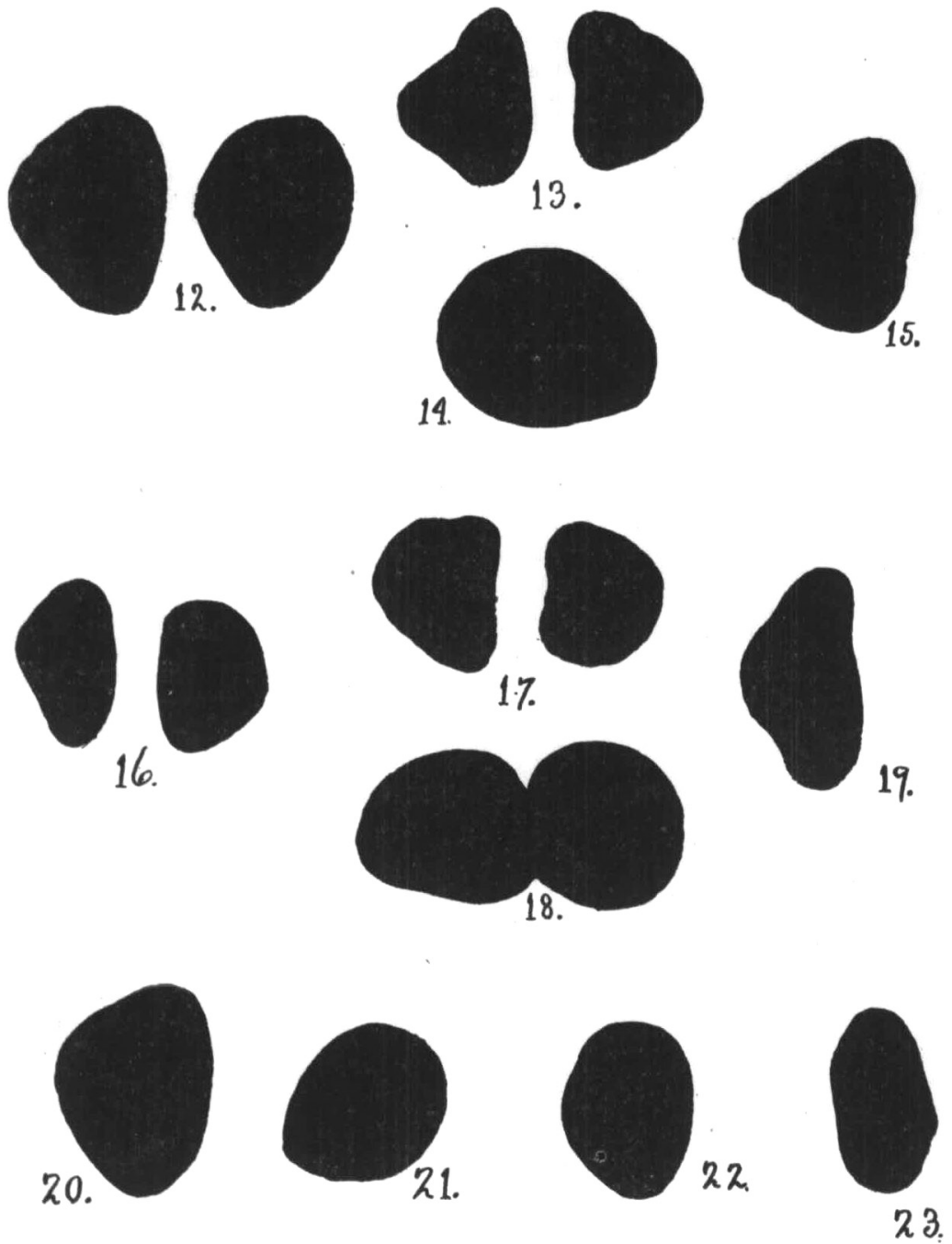

Downloaded from https://academic.oup.com/endo/article-abstract/5/6/763/2771563 by East Carolina University user on 04 April 2018 


\section{PLATE IV.}

Fig. 24. Median longitudinal section of the hypophysis of thymectomized frog.

Fig. 25. Median longitudinal section of the hypophysis of normal frog. 0.18 cc.).

Fig. 26. Hypophysis after thymectomy (frog, $12 \mathrm{~mm}$., vol.

Fig. 27. Hypophysis of normal frog (12 mm., vol. 0.20 cc.). 0.32 cc.).

Fig. 28. Hypophysis after thymectomy (frog, $13 \mathrm{~mm}$., vol.

Fig. 29. Hypophysis of normal frog $(13 \mathrm{~mm}$.$) .$ 0.30 cc.).

Fig. 30. Hypophysis after thymectomy (frog, 13:5 mm., vol.

Fig. 31. Hypophysis of normal frog (13.5 mm., vol. 0.33 cc.). 

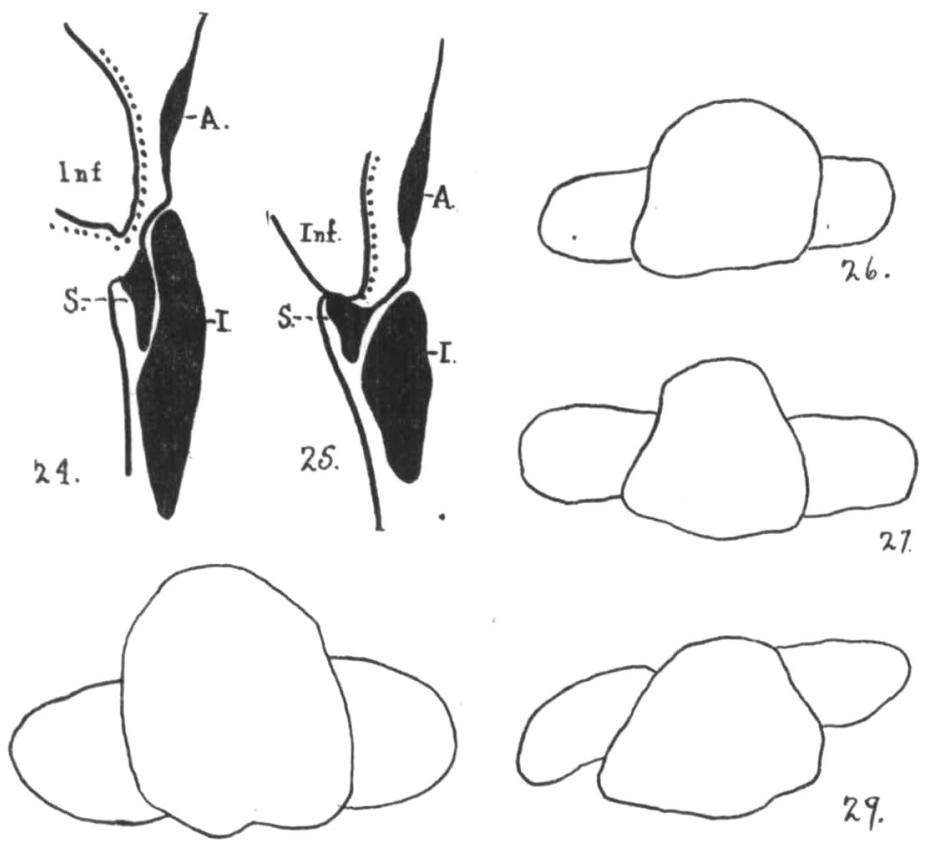

28.
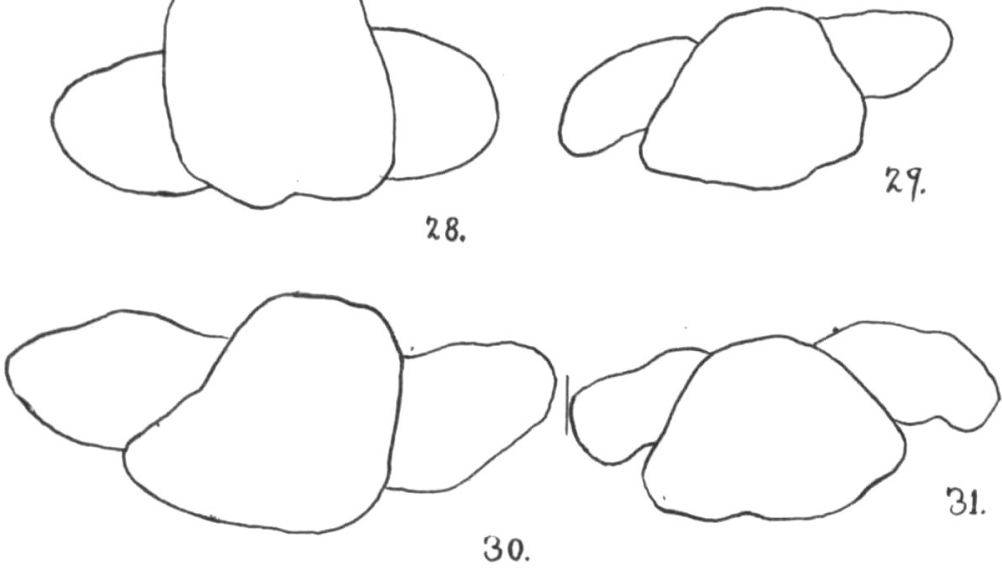
PLATE V.

Fig. 32. Testes after complete thymectomy (vol. of frog, $0.25 \mathrm{cc}$.).

Fig. 33. Testes after unilateral thymectomy (vol. of frog, 0.25 cc.).

Fig. 34. Testes of normal frog (vol. of frog, $0.20 \mathrm{cc}$.).

Fig. 35. Testes after grafting (vol. of frog, $0.20 \mathrm{cc}$.).

Fig. 36. Testes after complete thymectomy (vol. of frog, 0.38 cc.).

Fig. 37. Testes after unilateral thymectomy (vol. of frog, $0.35 \mathrm{cc}$.$) .$

Fig. 38. Testes of normal frog (vol. of frog, $0.37 \mathrm{cc}$. ).

Fig. 39. Testes after grafting (vol. of frog, $0.38 \mathrm{cc}$.). 

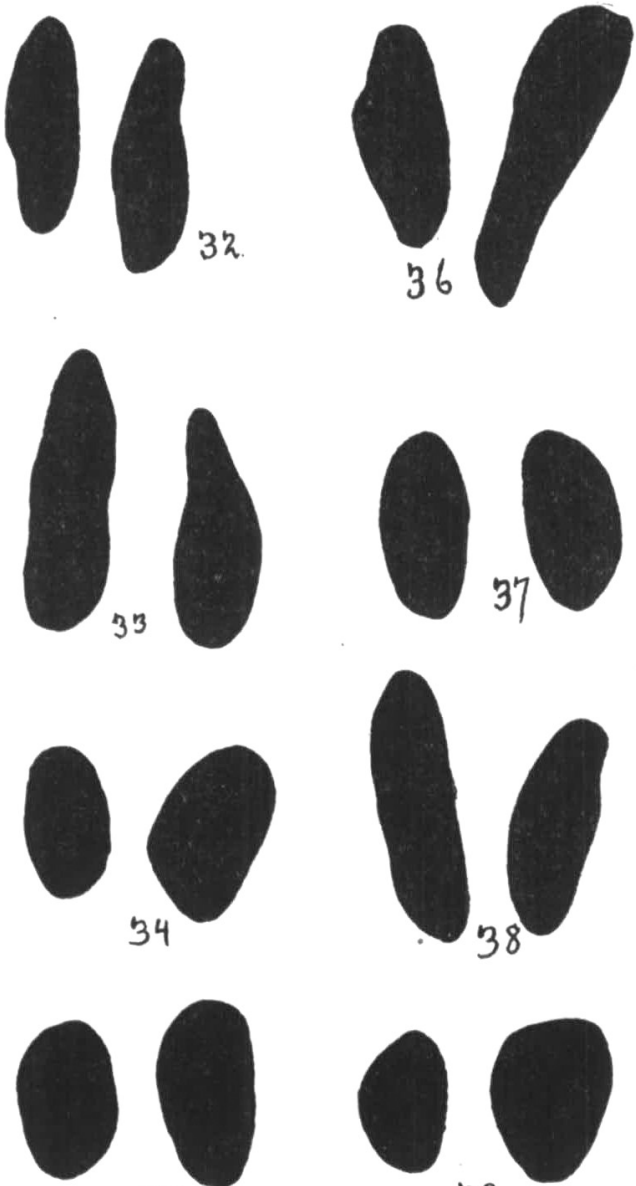

35

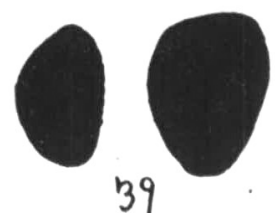

Downloaded from https://academic.oup.com/endo/article-abstract/5/6/763/2771563 by East Carolina University user on 04 April 2018 
Downloaded from https://academic.oup.com/endo/article-abstract/5/6/763/2771563 by East Carolina University user on 04 April 2018 